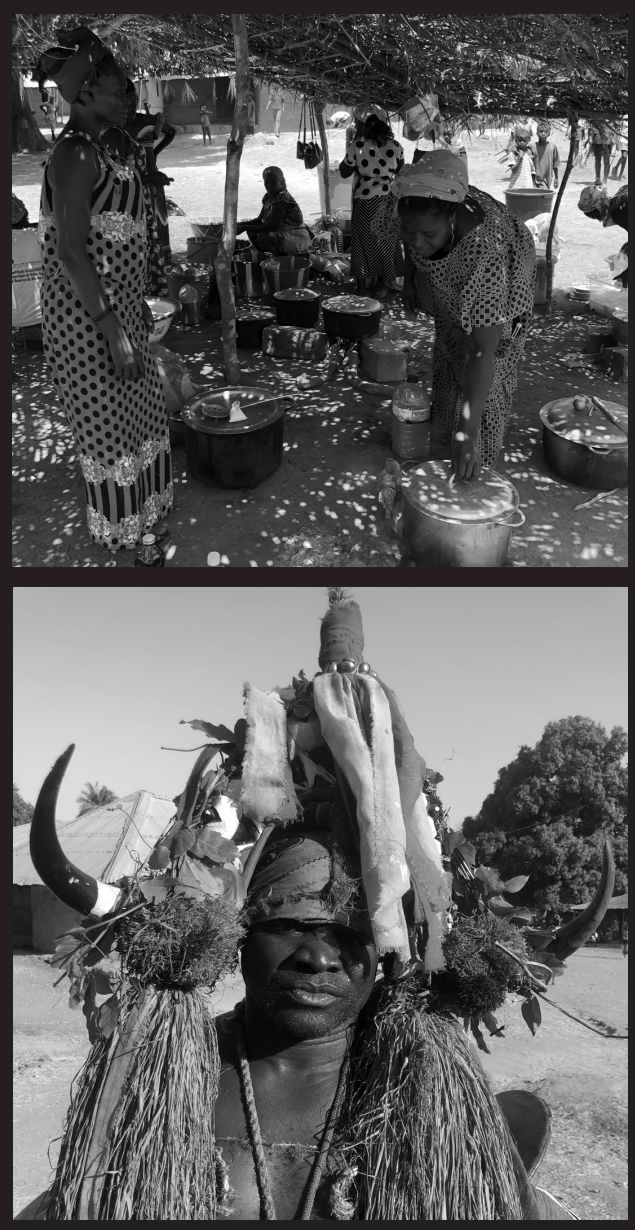

Tabanca de Bijante. Guiné Bissau

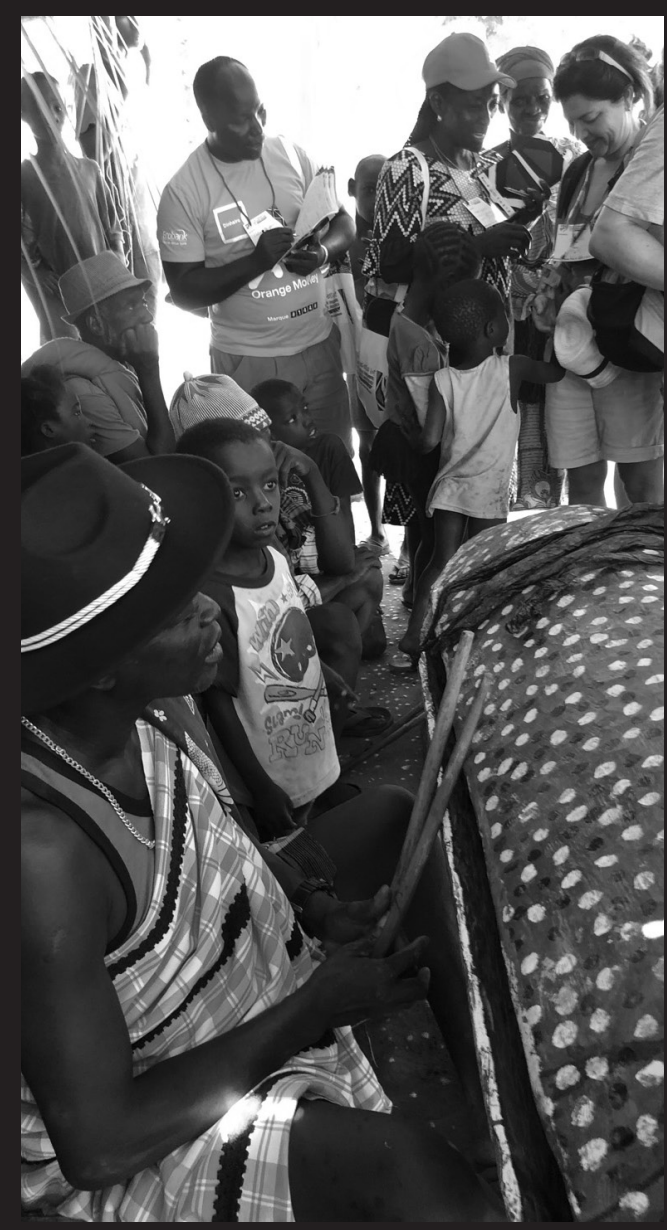

(C) Joaquim Pinto|ASPEA 
ISSN: 1887-2417 ISSN-e: $2386-4362$

https://doi.org/10.17979 /ams.2019.26.1-2.6548

\section{Implantação e consolidação de equipamentos para a educação}

\section{ambiental: Reflexões sobre estratégias \\ a delinear e a concretizar} Implementation and consolidation of equipment for environmental education: Considerations on strategies to be outlined and adopted

\author{
Margarida Correia Marques ${ }^{1}$ iD , Marcos Sorrentino² (iD e Araceli Serantes- \\ Pazos $^{3}$ (iD) 1. Universidade de Trás-os-Montes e Alto Douro (Portugal). 2. Universidade de São Paulo (Brasil). \\ 3. Universidade da Coruña (Galicia).
}

\section{Resumo}

Os equipamentos para a educação ambiental (EqEA) têm potencial para serem eficazes dinamizadores sociais e promoverem um desenvolvimento comunitário sustentável. No presente trabalho pretende-se dar a conhecer o livro intitulado "Equipamentos para a Educação Ambiental". Recorrendo a visitas in loco, a questionários, à fotografia profissional de António Borba e ao moderno e elegante design de Luís Gabriel, esta obra desvela dezasseis EqEA no interior Norte e Centro de Portugal Continental. Dirige-se a um público alargado, designadamente: educadores ambientais e responsáveis de EqEA, decisores, empreendedores, potenciais visitantes/utilizadores destes equipamentos. Objetiva contribuir para a premente reflexão e discussão sobre o papel deste recurso de educação ambiental -os EqEA-, no presente e num futuro próximo, bem como, no contexto da atual Estratégia Nacional de Educação Ambiental. Fruto do projeto "Equipamentos de educação ambiental para a sustentabilidade em prol de uma nova cultura da Terra”, envolveu na sua concretização as universidades: de Trás-os-Montes e Alto Douro (Portugal), de São Paulo (Brasil) e da Corunha (Galiza). Este livro aponta diretrizes, desafios e oportunidades, que podem impulsionar uma vivência socioambiental mais justa. Constata também que a existência de uma rede de EqEA é crucial na construção da equidade territorial, sobretudo em territórios de baixa densidade.

\section{Astract}

Facilities for Environmental Education (EqEA) has the potential of being an effective social facilitator, whilst stimulating a sustainable community development. The present paper aims to promote "Facilities for Environmental Education", a book that through site visits and surveys, alongside the professional photography of António Borba and the modern and elegant design of Luís Gabriel, unveils sixteen EqEA located in the inner northern and central continental Portuguese regions. The work targets a wide audience comprised of environmental educators and EqEA managers, decisionmakers, entrepreneurs and potential visitors/users of facilities. It intends to contribute towards an urgent reflection and discussion about the role of this environmental education resource -the EqEA- both in the present day and near future, in light of the 
current National Strategy for Environmental Education of Portufal. A result from the "Facilities for environmental education for a sustainable new Earth culture" project, which combined the efforts of the universities of Trás-os-Montes and Alto Douro (Portugal), São Paulo (Brazil) and A Coruña (Galicia), this book points out guidelines, challenges and opportunities that can foster a fairer socioenvironmental experience and underlines the need for an EqEA network to be developed, if territorial equity is to be achieved, especially in low density territories.

\section{Palabras chave}

Equidade territorial; Equipamento para a educação ambiental; Portugal Continental; Território de baixa densidade; Sustentabilidade.

\section{Key-words}

Territorial equity; Facilities for environmental education; Continental Portugal; Low density territory; Sustainability.

\section{Introdução}

A educação ambiental (EA) é considerada como um instrumento crucial na Agenda 2030, definida pela Organização das Nações Unidas, em 2015 (UN, 2019). Sendo transversal a vários dos 17 Objetivos de Desenvolvimento Sustentável (ODS), a EA é ainda determinante na capacitação das populações para intervirem nas decisões com impacte no meio envolvente, bem como no alavancar de políticas públicas de ambiente.

Os equipamentos para a educação ambiental(EqEA) -um conjunto de iniciativas heterogéneas que servem os propósitos da EA- têm mostrado um elevado potencial para serem eficazes dinamizadores sociais. Estes recursos de âmbito local podem ter um papel crucial na construção da equidade territorial, especialmente em áreas de baixa densidade populacional. Neste contexto, iniciou-se, em 2017, o projeto "Equipamentos de educação ambiental para a sustentabilidade em prol de uma nova cultura da Terra". Sob a coordenação da Unidade de Ambiente da UTAD -Universidade de Trás-os-Montes e Alto Douro (Portugal)-, este projeto está a ser concretizado com a colaboração da Facultade de Ciencias da Educación da Universidade da Corunha (Galiza) e do OCA-Laboratório de Educação e Política Ambiental da Universidade de São Paulo (Brasil).

No presente trabalho visa-se dar a conhecer um dos frutos do projeto acima mencionado: o livro intitulado "Equipamentos para a educação ambiental: um caminho de sustentabilidade no interior Norte e Centro de Portugal Continental". Esta obra foi editada pela UTAD, em dezembro de 2018 [(ISBN: 978-989-704-358-1 (impresso); 978-989704-359-8 (eletrónico)]. O prefácio ficou a cargo de Elizabeth Silva, responsável pelo 
Setor Ciência da Comissão Nacional da Organização das Nações Unidas para a Educação, Ciência e Cultura-UNESCO.

\section{O Livro "Equipamentos para a educação ambiental"}

\section{Antecedentes, público-alvo e objetivo}

Esta obra surge na sequência do Plano Regional de Desenvolvimento Integrado, concretizado para a área territorial denominada por CORREIA MARQUES et al. (2015) como o "cerne do EntreNorte-e-Centro". A forte aposta nos recursos endógenos para a construção da sustentabilidade neste território multimunicipal, levou a considerar a EA, em particular um dos seus recursos -os EqEAcomo um desafio, mas também como uma oportunidade (CORREIA MARQUES et al., 2017). Importa salientar que a área em análise no presente livro, além dos sete municípios que constituem o cerne do Entre-Norte-e-Centro, inclui outros territórios de baixa densidade do interior Norte e Centro de Portugal Continental.

Ao iniciar-se o estudo em que assentou a elaboração dos conteúdos deste livro, constatou-se que, nos territórios em análise, a grande maioria dos EqEA não se encontrava georreferenciado no SNIAmb
-Sistema Nacional de Informação de Ambiente- (APA, 2017). Desta constatação surge, nesta obra, o enfoque também na identificação e no registo online (voluntário e gratuito) de prováveis EqEA, de forma a serem validados pelos serviços da Agência Portuguesa do Ambiente (APA).

A nível de políticas públicas, a Estratégia Nacional de Educação Ambiental (ENEA 2020), publicada em 2017 para o período até 2020, considera os EqEA como recursos importantes de EA (Resolução do Conselho de Ministros n. ${ }^{\circ}$ 100/2017 de 11 de julho). Esta estratégia aponta para três eixos temáticos e transversais de atuação, encaminhando-se, esta obra, diretamente para um deles -valorizar o território-, com possíveis impactes nos outros dois: descarbonizar a sociedade e tornar a economia circular.

A obra dirige-se a um público alargado, nomeadamente: educadores ambientais e responsáveis de EqEA, decisores, empreendedores e potenciais visitantes e utilizadores destes equipamentos. O seu principal objetivo é contribuir para a premente reflexão e discussão sobre o papel dos EqEA, no presente e num futuro próximo, bem como no contexto da ENEA 2020.

\section{Design gráfico e capa}

O design gráfico do livro esteve a cargo do designer Luís Gabriel. Uma condição 
importante foi o livro ser, em paralelo, moderno, elegante e muito apelativo, transmitindo ideia de mudança e de adoção de novos comportamentos com vista à construção de um futuro mais sustentável nos territórios em análise.

A capa foi concebida para se identificar, através da cor e da imagem, uma relação entre o ambiente e os equipamentos, apelando assim à curiosidade sobre o assunto em foco na obra. A partir de uma fotomontagem assumida de duas fotografias de tipos distintos de EqEA -um edifício e um parque-, foi construída uma imagem muito elegante e sóbria, em tons da natureza com predominância para o verde, que ilustra claramente a temática do livro (ver Figura 1, embora a preto e branco).

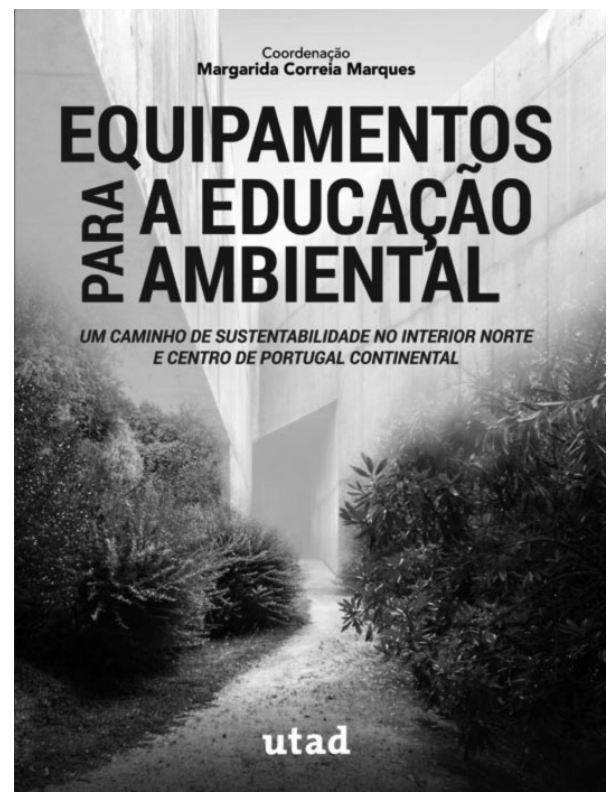

Figura 1: Capa do livro "Equipamentos para a Educação Ambiental" (a cores no original), 2018.
As dimensões do livro $(18,5 \mathrm{~cm}$ largura x 24,7 cm altura) e a sua espessura (232 páginas) foram definidas tendo em vista a facilidade no manusear e transportar.

\section{Elaboração de conteúdos}

Para a construção dos conteúdos relativos aos EqEA descritos, recorreuse a: publicações impressas e digitais; consulta de portais de internet e redes sociais; visitas de estudo às instalações dos equipamentos; inquéritos dirigidos às entidades gestoras; realização de fotografias dos espaços exteriores e interiores, bemcomo doseuenquadramento paisagístico. Adicionalmente realizaramse reuniões com os responsáveis diretos e/ou entidades gestoras, que, sem exceção, disponibilizaram as informações necessárias e se prontificaram a validar os textos com as descrições dos equipamentos.

Aplicou-se um questionário para a identificação de potenciais EqEA que visava, por um lado, a georreferenciação do EqEA pela APA, em dezembro de 2018, e por outro, a divulgação do relevante papel educativo que estas estruturas desempenham na promoção da cidadania ambiental e no desenvolvimento sustentável. Este questionário tem sete subdivisões: Identificação do equipamento (missão, objetivos, horário de funcionamento, morada, acessibilidade, portal de Internet 
e redes sociais, entidade responsável etc.); Infraestrutura/Organização (ano de início de funcionamento, instalações que ocupa, serviços disponíveis ao público, entre outros); Recursos humanos (nomeadamente: número de elementos e respetiva formação da equipa educativa, projeto(s) educativo(s) e atividades); Gestão (como entidade responsável e número aproximado de visitantes/ utilizadores no último ano); Relações com o exterior/Comunicação (por exemplo: divulgação/publicitação, integração e/ ou colaboração com outras entidades, principais dificuldades/carências).

O trabalho no terreno decorreu entre setembro de 2017 e outubro de 2018. Todas as entidades gestoras dos EqEA apresentados no livro permitiram que o fotógrafo António Borba visitasse as instalações do equipamento para fazer captação de imagens. As fotografias foram realizadas com o intuito de mostrar, principalmente, o potencial dos espaços que cada EqEA coloca à disposição dos seus visitantes/utilizadores. Por esta razão, as imagens ilustram, sobretudo, espaços sem pessoas, embora tenha sido dado um especial enfoque àqueles onde decorrem atividades de EA. A paisagem envolvente também foi considerada.

\section{Estrutura e forma}

Este livro é constituído por oito capítulos. Após o capítulo 1 "Introdução", o capítulo
2 enquadra a temática, revelando especificidades nacionais. Nos capítulos 3 a 7 descrevem-se EqEA, sediados no Norte e Centro de Portugal Continental. Em jeito de conclusão, além do capítulo 8 resumir os principais contributos do diagnóstico realizado, essencialmente aponta diretrizes, desafios e oportunidades, que podem impulsionar uma vivência socioambiental mais justa, nos territórios analisados. Em anexo encontram-se: - questionário para "Identificação de potenciais equipamentos para a educação ambiental"; um curto glossário sobre a tipologia dos EqEA.

O texto foi redigido de forma simples, positiva e sucinta para ser compreensível por todos os públicos e, simultaneamente, os cativar, mobilizar e fazer diferença no(s) seu(s) olhar(es) os territórios e a sustentabilidade.

\section{Equipamentos para a educação ambiental no interior Norte e Centro de Portugal Continental}

A pequena mostra -dezasseis EqEA-, que se desvela nesta obra, é uma "fotografia" atual e o testemunho das potencialidades presentes, as quais podem ser desafios e oportunidades com significado para o futuro mais coeso, próspero e sustentável, 
que se visa construir nos territórios de baixa densidade analisados. Na introdução do livro é mencionado que os principais critérios para a seleção dos equipamentos, a integrar a obra, foram: "estarem sediados no Norte e Centro interior de Portugal Continental; funcionarem com uma oferta educativa permanente, que inclui a perspetiva ambiental; as suas peculiaridades identitárias locais; o seu ímpar património natural, histórico, arquitetónico e/ou cultural; e a inovação" (CORREIA MARQUES et al., 2018:4).

Os diversos equipamentos foram agrupados nos capítulos por temáticas gerais abordadas e ligação ao território onde estão implantados. Assim sendo, constam do capítulo 3 "Experienciar ciência": Plataforma de Ciência Aberta, Centro de Ciência de Vila Real, Centro Ciência Viva de Bragança"; do capítulo 4 "O presente do passado": Museu do Côa, Museu do Quartzo, Casa das Pedras Parideiras; do capítulo 5 "Produtos desvelando territórios": Museu do Douro, Núcleo Museológico de Favaios - Pão e Vinho, Museu do Vinho de São João da Pesqueira, Museu do Pão; do capítulo 6 "Interpretando o património": Centro de Interpretação e Informação do Montemuro e Paiva, Centro Pedagógico e Interpretativo da Rede Natura de Lamosa, Museu Rural de Pendilhe (ver Figura 2); e, por fim, do capítulo 7 "Atividades no Parque": Parque Botânico Arbutus do Demo, Parque Biológico de Vinhais, Passadiços do Paiva. Para a presente obra, não se revelou

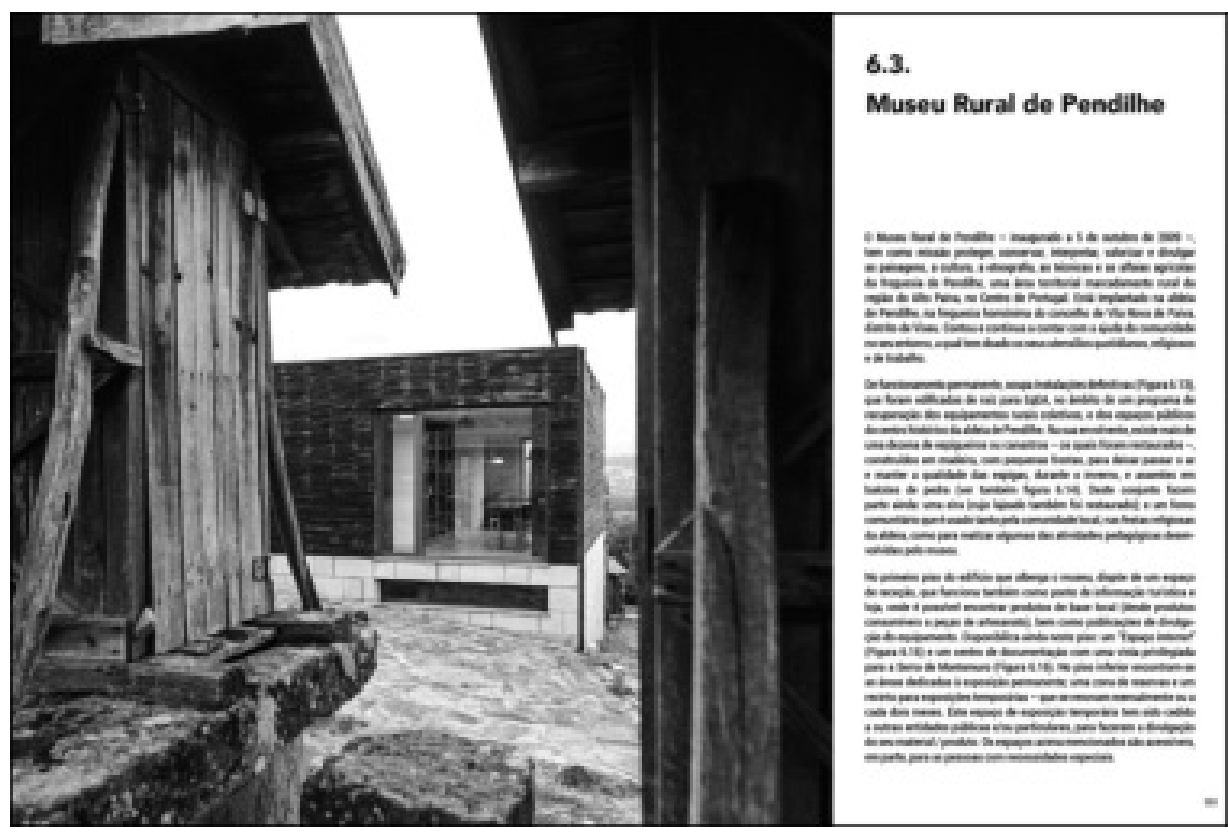

Figura 2: Início de subcapítulo para apresentação de um equipamento (a cores no original; CORREIA MARQUES et al., 2018:150-151). 
determinante, a divisão dos EqEA em tipologias (agrupamento de tipos de equipamento, segundo as designações ou funções principais). Este facto, como salientado por CORREIA MARQUES et al. (2018:10), deve-se, por um lado, "à falta de um estudo aprofundado, que abranja toda a diversidade de iniciativas da realidade portuguesa, permanecendo um campo muito volátil e frágil, na área dos recursos em EA. Por outro lado, esta questão talvez não se mostre em si relevante, desde que os propósitos e objetivos da EA sejam cumpridos". De qualquer forma, no glossário sumário, que consta do anexo "Informações complementares", são expostas as definições delineadas a nível legislativo ou construídas pelos EqEA e autores deste livro (ver também

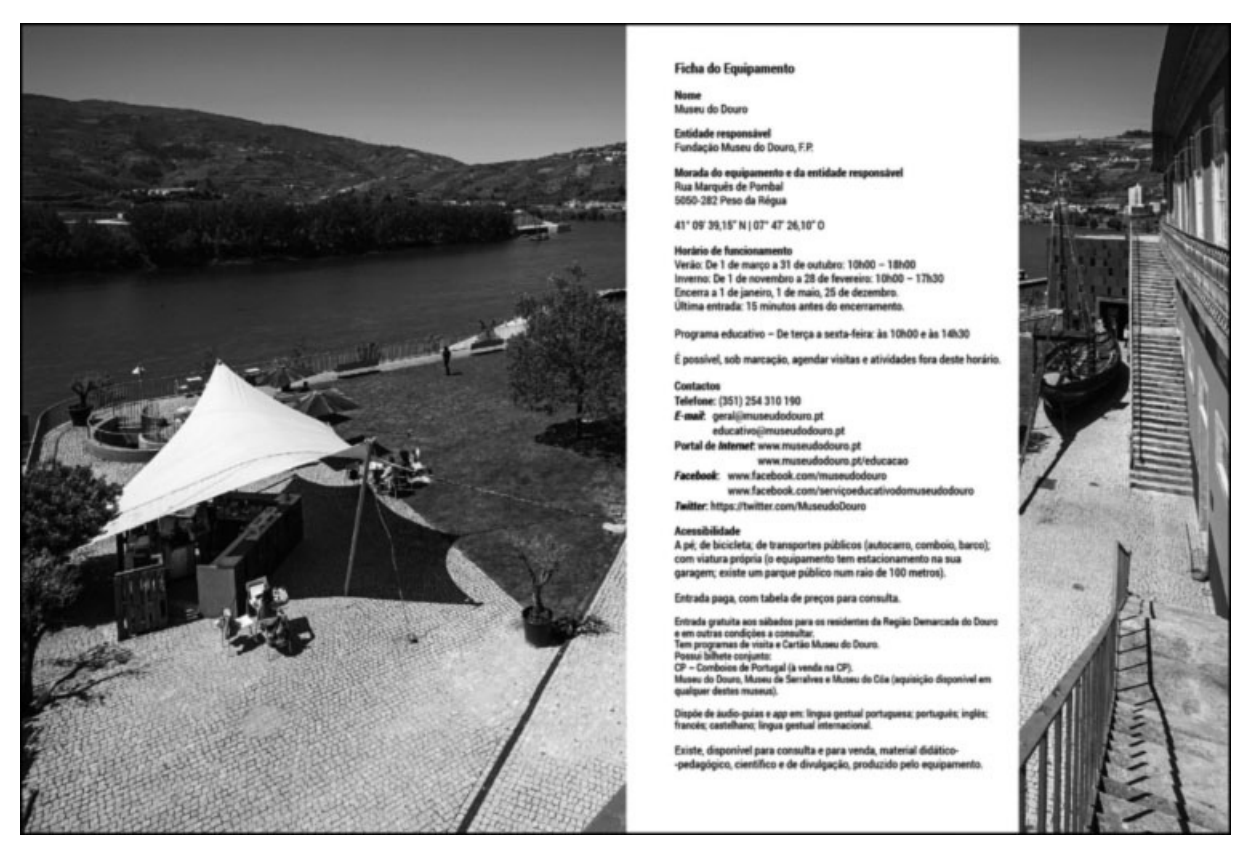

Figura 3: Ficha do equipamento no final da respetiva descrição (a cores no original; CORREIA MARQUES et al., 2018: 94-95). subcapítulo 2.4).

A descrição dos diferentes EqEA segue uma estrutura sensivelmente semelhante: missão; caraterização do(s) edifício(s) e dos espaços interiores; entidade gestora; equipa educativa; atividades desenvolvidas; colaborações formais e informais; avaliação do equipamento e do projeto educativo; número de visitantes/utilizadores no último ano de funcionamento (2017/2018); as maiores carências identificadas pelo EqEA. A apresentação termina com a "Ficha do equipamento", a qual contém informação útil sobre o mesmo (como a(s) morada(s) e os contactos do EqEA e da respetiva entidade gestora, os horários de funcionamento; confrontar Figura 3). 
A simplicidade, clareza e objetividade, tanto das fotografias como do design gráfico, permitem exibir a modernidade e atualidade destes recursos que transmitem ao visitante/utilizador a vontade de permanecer e de participar nas atividades que the são oferecidas. Como referido no subcapítulo 2.3 , as imagens, que acompanham o texto de caraterização dos EqEA, desvelam o exterior das instalações e o potencial dos principais espaços interiores (Figura 4), bem como as paisagens que os visitantes podem disfrutar a partir do equipamento.

Os autores do livro verificam que apesar de nem sempre os equipamentos em análise se nomearem como EA

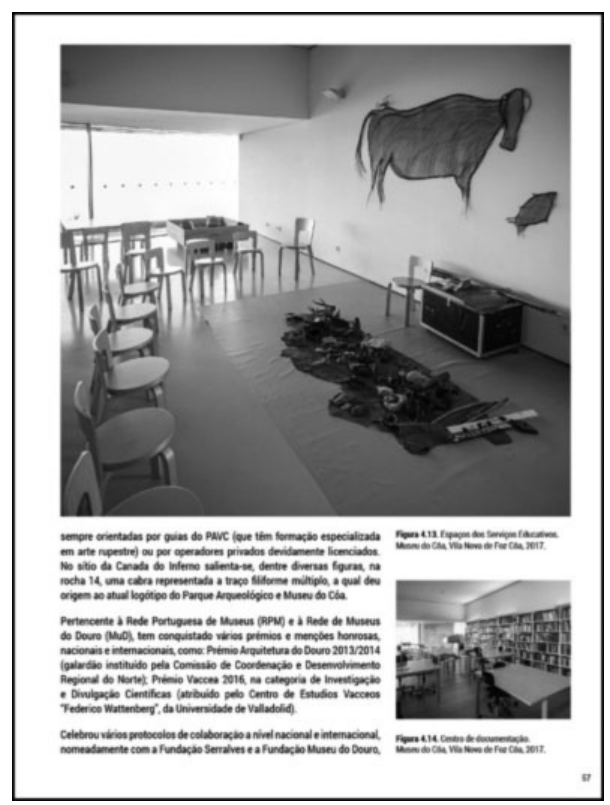

Figura 4: Espaços interiores de um equipamento (a cores no original; CORREIA MARQUES et al., 2018:57). e/ou se comprometerem, imediata e explicitamente, com as medidas estratégicas e os eixos apontados pela ENEA 2020 "há um enorme potencial para que se tornem os principais agentes locais, emuladores de uma nova cultura da Terra, essencial para se enfrentarem os desafios deste período de transição educadora, em direção a sociedades sustentáveis" (CORREIA MARQUES et al., 2018:5). Adicionalmente constatam que uma equipa multidisciplinar de elevada qualificação (nível de instrução, experiência e formação contínua) é determinante para que o EqEA seja criativo e inovador, se reinvente e renove, antecipando-se aos desafios apresentados e às oportunidades latentes. Salientam que à semelhança da generalidade do universo dos EqEA, uma lacuna importante, comum à maioria dos equipamentos incluídos na obra, é a avaliação, designadamente a das atividades educativas. Deixam o repto para que, num futuro próximo, se construam indicadores de monitorização e avaliação de projetos, bem como de políticas públicas de EA, em Portugal.

Importa referir que nestes EqEA, conciliar, de forma integrada, a vertente da EA com outras vertentes socioeconómicas, se revela muito positiva, tanto no aumento da multiplicidade de segmentos da comunidade local que envolvem, como na maior capacidade para atrair visitantes/ utilizadores e, em consequência, no gerar de riqueza e emprego. Este facto 
é especialmente notório quando são disponibilizados serviços de excelência, por exemplo, no domínio da restauração (Figura 5).

Em paralelo, estão a procurar construir redes eficazes e inteligentes, e/ou fortalecer conexões sinérgicas entre si, bem como entre este tipo de recursos de EA e os agentes ambientais, sociais e económicos. A título exemplificativo, refirase as visitas conjuntas já disponíveis, com aquisição de um só ingresso de entrada, como: Museu do Douro, Museu do Côa e Museu de Serralves; Museu do Côa e Museu da Casa Grande de Numão de Freixo.

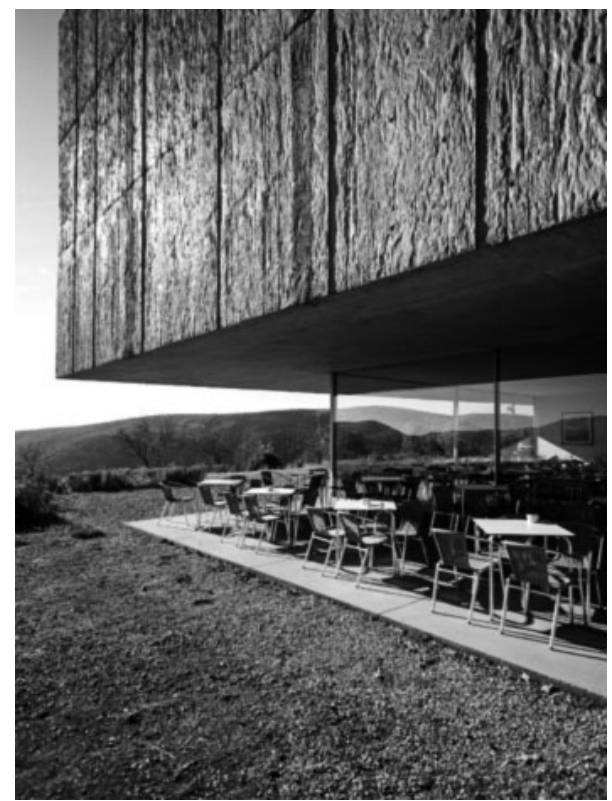

Figura 5: Esplanada do restaurante do Museu do Côa (a cores no original; CORREIA MARQUES et al., 2018:59)

\section{Considerações finais}

Nos territórios de baixa densidade do Norte e Centro de Portugal Continental-marcados por tendências demográficas, económicas e ambientais de perda-, nos últimos dez anos, tem-se observado um grande dinamismo em termos de abertura de novos EqEA, localizados em meio natural, rural ou urbano. Estes equipamentos tornaram-se, ou estão a tornar-se, recursos-âncora das suas áreas de influência. Contudo, impõese que tenham flexibilidade e abertura, para adaptar as suas estruturas organizacionais às exigências das sociedades contemporâneas, nas quais as mudanças ocorrem a ritmos muitos rápidos e se refletem em diversos contextos, incluindo na EA. Implica também que levem em conta a intersetorialidade das políticas públicas, nas ações educativas. Não havendo qualquer antítese entre património, identidades locais e processos de inovação, há ainda que manter em permanente construção o espaço de oportunidades originado por estes equipamentos, incluindo projetos complementares ou similares.

Tanto para a obtenção de recursos como para a atração de visitantes/ utilizadores, é imprescindível intensificar o desenvolvimento e a consolidação de estratégias colaborativas, que se mostram ainda muito aquém do seu potencial. Sendo a transferência de conhecimento uma mais-valia para a equidade socioambiental, 
corrobora-se a importância de existir "uma plataforma que reúna e disponibilize os projetos educativos e respetivas atividades inovadoras -conteúdos teóricos e a realização prática-, desenvolvidos e concretizados pelos diferentes EqEA. Esta partilha permitirá que outros equipamentos possam usar essas ideias inovadoras e/ ou práticas excelentes, adaptando-as às suas realidades" (CORREIA MARQUES et al., 2018:205). Esta plataforma, autónoma ou associada a outras bases de dados já existentes, a nível nacional, poderá ficar sob a responsabilidade da APA, por exemplo, integrada no SNIAmb; ou pode ficar sob a alçada de uma outra organização, nomeadamente um EqEA específico.

Verifica-se que existe ainda potencial de crescimento tanto em número de EqEA, como em capacidade de visitantes/ utilizadores, vertentes e domínios de atuação destes equipamentos. Porém, é crucial que TODOS, dos EqEA (existentes ou a implantar) aos decisores políticos e visitantes/utilizadores, estejam intrinsecamente vinculados e comprometidos com a transformação, a emancipação e a liberdade.

\section{Agradecimentos}

Ao designer Luís Gabriel é expressada sentida gratidão pela elaboração das figuras a preto e branco. Reconhece-se o financiamento por Fundos Nacionais através da FCT-Fundação para a Ciência e a Tecnologia, no âmbito do projeto UID/AGR/04033/2019.

\section{Referências bibliográficas}
APA-Agência Portuguesa do Ambiente, I.P. (2017). SNIAmb-Sistema Nacional de Informação de Ambiente, Agência Portuguesa do Ambiente, I.P. [http:// www.apambiente.pt/index.php?ref $=$ 16\&subref=142\&sub2ref=698 http:// sniamb.apambiente.pt [Acedido em se- tembro de 2017].

CORREIA MARQUES, Margarida, Araceli SERANTES, Fátima MARQUES, Marcos SORRENTINO, Maria Inês VICENTE, Pedro RUSSO e Sara CARVALHO. (2018). Equipamentos para a educação ambiental. Um caminho de sustentabilidade no interior Norte e Centro de Portugal Continental. Vila Real: UTAD- Universidade de Trás-os-Montes e Alto Douro.

CORREIA MARQUES, Margarida, Fabiola HIPÓLITO e Rosanno BASTOS (2017). "Os equipamentos de educação ambiental para a sustentabilidade no cerne do Entre-Norte-e-Centro", AmbientalMente Sustentable. Revista Científica Galego-Lusófona de Educación Ambiental, XII,23-24 (1-2), páj. 119-139.

CORREIA MARQUES, Margarida, A. MARTINS, A. MASCARENHAS, A.P. SILVA, A.C. RODRIGUES, C. RODRIGUES, C. SÁ, F. HIPÓLITO, F. MARQUES, I. BRANCO, J. BAPTISTA, J. JORGE, J. ARANHA, N. BARROS, O. SANTANA, S. LOBO, S. MESQUITA, S. LEITE, e V. SEIXAS (2015): Sete concelhos, um território: uma caraterização ambiental e socioeconómica no cerne do Entre-Norte-e-Centro. Cascais: Princípia.

RESOLUÇÃO DO CONSELHO DE MINISTROS n. ${ }^{\circ}$ 100/2017 de 11 de julho. Estratégia Nacional de Educação Ambiental em Diário da República, $1 .^{a}$ série, n. ${ }^{\circ} 132$, 3533-3550.

UN-United Nations (2019). Sustainable Development Goals. [Acedido em julho de 2019: https://www.un.org/sustainabledevelopment/sustainable-development-goals]. 